\title{
VIVÊNCIA DE PROFISSIONAIS DE ENFERMAGEM NO RESPEITO AOS DIREITOS HUMANOS NAS RELAÇÕES DE CUIDADO
}

\section{EXPERIENCE OF NURSING PROFESSIONALS IN RESPECT FOR HUMAN RIGHTS IN CARE RELATIONS}

\section{EXPERIENCIA DE PROFESIONALES DE ENFERMERÍA EN EL RESPETO DE LOS DERECHOS HUMANOS EN LAS RELACIONES CON LA ATENCIÓN}

Tyciana Paolilo Borges ${ }^{1}$, Karla Ferraz dos Anjos², Mariana Oliveira Antunes Ferraz ${ }^{3}$, Joise Magarão Queiroz Silva ${ }^{4}$, Darci de Oliveira Santa Rosa ${ }^{5}$, Carlito Lopes Nascimento Sobrinho ${ }^{6}$

\section{RESUMO}

Objetivo: Compreender como as profissionais de enfermagem vivenciam o respeito aos direitos humanos nas relações de cuidado. Método: Estudo fenomenológico, realizado com 11 profissionais de enfermagem que atuavam em um serviço de emergência. A coleta de dados ocorreu, por meio de entrevista, com análise a partir da configuração triádica humanístico-existencial-personalista. Resultados: o respeito aos direitos humanos nas relações de cuidado, vivenciado por profissionais de enfermagem, em unidade de emergência, foi descrito no acolhimento ao usuário, respeito, diálogo, cuidado integral, esforços para a garantia dos direitos, limites do cuidado e preconceitos nas relações. Conclusão: Desvelou-se a prática social das profissionais de enfermagem que atuavam em unidade de urgência, a partir de um fazer cotidiano, com respeito aos direitos humanos na busca da integralidade do cuidado aos usuários do serviço, mesmo ante os limites institucionais e inadequações estruturais e organizacionais do serviço.

Descritores: Cuidados de Enfermagem; Equipe de Enfermagem; Direitos Humanos; Emergências.

\begin{abstract}
Objective: To understand how nursing professionals experience respect for human rights in care relations. Method: this is a phenomenological study. Eleven nursing professionals working in an emergency department participated in the study. The analysis was guided by the Humanistic, Existential and Personalist configuration. Results: The theme "respect for human rights" in care relations by nursing professionals in emergency rooms was described as embracement, respect, dialogue, integral care, efforts to guarantee rights, limits of care and prejudice in relationships. Conclusion: The social practice of nursing professionals working in an emergency room was demonstrated by their daily work that expresses a relationship with respect for human rights, even in unfavorable contexts, where this need is further evident.
\end{abstract}

Descriptors: Nursing Care; Nursing Team; Human Rights; Emergencies.

\section{RESUMEN}

Objetivo: Entender cómo los profesionales de enfermería experimentan el respeto de los derechos humanos en las relaciones de cuidados. Método: Estudio fenomenológico. En el estudio participaron once profesionales de enfermería que trabajan en un servicio de emergencia. El análisis fue guiado por la configuración humanística, existencial y personalista. Resultados: El respeto de los derechos humanos en las relaciones de atención vividas por los profesionales de enfermería en una unidad de emergencias fue descrito en la recepción al usuario, respeto, en el diálogo, atención integral, esfuerzos para garantizar los derechos, límites de atención y prejuicios en las relaciones. Conclusión: Se revela la práctica social de los profesionales de enfermería que trabajan en un servicio de emergencia, basada en una práctica diaria que expresa una relación con el respeto a los derechos humanos, incluso en contextos desfavorables, donde esta necesidad es más evidente.

Descriptores: Atención de Enfermería; Grupo de Enfermería; Derechos Humanos; Urgencias Médicas.

${ }^{1}$ Enfermeira. Intensivista. Mestre em Enfermagem. Programa de Pós-Graduação em Enfermagem e Saúde, Universidade Federal da Bahia. ${ }^{2}$ Enfermeira. Pós-Doutoranda em Enfermagem e Saúde. Programa de Pós-Graduação em Enfermagem e Saúde, Universidade Federal da Bahia. ${ }^{3}$ Enfermeira. Mestre em Ciências da Saúde. Doutoranda do Programa de Pós-Graduação em Enfermagem e Saúde, Universidade Federal da Bahia. ${ }^{4}$ Enfermeira. Mestre em Enfermagem. Doutoranda do Programa de PósGraduação em Enfermagem e Saúde da Universidade Federal da Bahia. ${ }^{5}$ Pós-Doutorado em Bioética pela Universidade dos Açores (Portugal). Professora do Programa de Pós-Graduação da Universidade Federal da Bahia. ${ }^{6}$ Professor Titular do Departamento de Saúde da Universidade Estadual de Feira de Santana. ]; Available in: DOI: 


\section{INTRODUÇÃO}

Após a Segunda Guerra Mundial, aumentou-se a necessidade de se pensar e refletir sobre os direitos e o respeito à dignidade humana. Assim, a criação, implantação e difusão da Declaração Universal dos Direitos Humanos (DUDH), em 1948, pela Organização das Nações Unidas (ONU) foi importante para a consolidação dos direitos individuais e construção de inúmeros documentos com vista aos direitos das pessoas, dentre eles, a Constituição da República Federativa do Brasil, promulgada em 1988.

Em seu preâmbulo, a DUDH considera o reconhecimento da dignidade a toda pessoa e família; o respeito pelos direitos humanos; o gozo, por parte de todas as pessoas, da liberdade de expressão e crença; a proteção dos direitos humanos pelas leis e que a compreensão dos direitos e da liberdade é importante para o pleno cumprimento do respeito universal e observância dos direitos e liberdades humanas ${ }^{(1)}$.

Em contraste, as vulnerabilidades expressas nas situações de saúde da população, nos fatores de riscos e acessos aos serviços de saúde, em que é reconhecida a produção social da doença, divergem na essência do proposto pela própria Carta Magna brasileira ou pela ONU. A expressão dessa realidade vem reforçada pela necessidade de apoiar iniciativas, para promover a humanização nos espaços de saúde, em uma tentativa de resgatar o reconhecimento da dignidade das pessoas, como pressupõe sua origem filosófica, o humanismo ${ }^{(2)}$.

$\mathrm{Na}$ perspectiva legal, o princípio da proibição de retrocesso social embarga a possibilidade de revogação de direitos fundamentais das pessoas, no sentido de não haver retorno às situações de atrocidades já vivenciadas ${ }^{(3)}$, Ao mesmo tempo, as desigualdades sociais e econômicas violam o direito à saúde e influenciam no acesso das pessoas aos serviço ${ }^{(4)}$ pois a renda, a classe social e a escolaridade, quando desfavoráveis, estão diretamente associadas às péssimas condições de saúde ${ }^{(5)}$. Assim, é a partir dos direitos humanos que as populações vulneráveis encontram fundamentação para lutar por seus direitos ${ }^{(6)}$, como o da saúde. Essas observações elevam o valor das considerações na contextualização das relações do cuidado em saúde.

No entanto há violação dos direitos humanos, nos contextos de cuidados, inclusive quando não são oferecidas condições adequadas de atendimento nos espaços de assistência à saúde. Na realidade brasileira, ambientes de trabalho com condições insatisfatórias estão relacionados também ao desgaste do profissional de saúde, o qual repercute na qualidade da assistência ${ }^{(7)}$ e incide na segurança do paciente. Isso inclui os serviços de urgência.

Optou-se em utilizar o termo urgência, para delimitar as situações e cenários dos atendimentos às pessoas diante dos agravos que exigem intervenção imediata, característica da urgência e emergência, conforme adotado pelos textos do Ministério da Saúde. Alguns entraves são apontados nesses cenários, como o processo de trabalho fragmentado, alta demanda de atendimentos e desrespeito aos direitos dos usuários ${ }^{(8)}$, o que promove um ambiente de saúde com desafios a serem superados.

Por ser a enfermagem uma profissão que presta cuidados às pessoas, seus trabalhadores enfermeiras, técnicos e auxiliares de enfermagem - devem conhecer, reconhecer e colocar em prática, nas suas decisões, a garantia dos direitos humanos aos serviços de saúde ${ }^{(9)}$.

As profissionais de enfermagem devem vivenciar os direitos das pessoas a quem prestam cuidados, tendo como referência a DUDH, bem como a Carta de Direitos dos Usuários da Saúde e no Código Internacional de Ética para as enfermeiras, no sentido de engajamento em prol de condições apropriadas de cuidado. É importante a reflexão sobre estes documentos, pois, nos serviços de saúde, esses profissionais se deparam com situações de desrespeito aos direitos das pessoas, como desvelados em situações de preconceito e discriminação ${ }^{(10)}$.

A escassez de pesquisas que revelem as experiências das profissionais de enfermagem sobre o respeito aos direitos humanos, nas relações de cuidado no contexto hospitalar, justifica a realização deste estudo. Logo é necessária a compreensão sobre como ocorre o respeito aos direitos humanos, nos serviços de saúde, especialmente nas unidades de urgências hospitalares, pela equipe de enfermagem, contribuindo para o cuidado humanizado, digno e ético.

Objetivou-se compreender como as profissionais de enfermagem vivenciam o respeito aos direitos humanos nas relações de cuidado.

\section{MÉTODOS}

Trata-se de um estudo fenomenológico originado dos resultados da dissertação de mestrado "Direitos humanos vivenciados pelos 
profissionais de enfermagem no cuidado à pessoa hospitalizada", na qual foi evidenciada a estrutura do fenômeno com sua temática, categoria e subcategorias emergidas.

Desenvolveu-se no setor da urgência de um hospital de grande porte de Salvador, referência do estado da Bahia, selecionado por atender exclusivamente ao Sistema Único de Saúde (SUS) e a uma população menos favorecida que vivenciam condições de vulnerabilidade e que podem estar susceptíveis à violação dos direitos humanos.

Participaram do estudo 11 profissionais de enfermagem, dentre os quais três enfermeiras e oito técnicas de enfermagem; das técnicas três eram do gênero masculino, abordadas presencialmente pela pesquisadora e selecionadas, conforme sua disponibilidade para a entrevista, sem contato prévio da pesquisadora com as participantes.

Os critérios de inclusão definidos foram: atuar na assistência da unidade de urgência do hospital; estar formada há pelo menos dois anos; trabalhar no turno matutino e/ou vespertino. Foram excluídas as que estavam de férias, licença, folga, afastadas ou indisponíveis no momento da coleta.

A coleta de dados se deu pela entrevista fenomenológica, realizada entre fevereiro e março de 2015, guiada por um roteiro previamente elaborado, composto por dados pessoais de caracterização e pela questão norteadora "Fale-me como você vivencia o respeito aos direitos humanos no cuidado à pessoa hospitalizada?"

A fenomenologia permitiu apreender as vivências das profissionais de enfermagem sobre o respeito aos direitos humanos na prestação de cuidados, a partir de suas experiências tais como são orientados pela consciência sobre 0 fenômeno, proporcionada na descrição da experiência. Assim, foi preciso orientar-se ao que foi dado à consciência, com exclusão daquilo que pode modificá-la, como o subjetivo das pesquisadoras e o objetivo que não é dado realmente no fenômeno considerado ${ }^{(11)}$.

Após o aceite do convite, a participante escolhia um local privativo para a realização da entrevista e, após a assinatura do Termo de Consentimento Livre e Esclarecido, a coleta de dados foi iniciada e registrada em um gravador de áudio portátil. Ao questionar, as participantes tiveram tempo livre para responder à pergunta, sem interrupções.
A fim de garantir o sigilo e a confidencialidade dos relatos, foram atribuídos codinomes de flores, conforme significado dos depoimentos. Enfermeiras (Gérbera, Dália, Bromélia) e técnicas de enfermagem (Açafrão, Frésia, Urze, Jacinto, Rosa Champanhe, Girassol, Orquídea, Magnólia). Assegurou-se o sigilo, anonimato e o direito das profissionais de se recusarem a participar do estudo, antes, durante ou após a coleta dos dados.

Ao término da entrevista, foi permitido às depoentes ouvirem suas falas para confirmação e/ou alteração do que considerassem necessário. Posteriormente, as entrevistas foram transcritas na íntegra. Não houve necessidade de teste-piloto para este estudo, uma vez que as informações emergiam, a partir das singularidades de cada consciência e experiência vivida.

A análise dos dados foi guiada pela configuração Triádica Humanística-ExistencialPersonalista que possibilitou a apreensão da essência das depoentes. "O fenômeno passa a ser analisado em suas singularidades, deixando de lado as generalizações"(12). Esse tipo de análise foi utilizado, a partir das informações fornecidas pelas participantes, coletadas em entrevistas, sistematizando seus conteúdos e expressões.

A análise seguiu as etapas: 1) Leitura atenta do conteúdo manifesto pelas participantes, de forma a apreender o significado dentro da estrutura global; 2) Releitura do texto, com a finalidade de identificar as unidades de significado, apreendidas por meio de um processo analítico-associativo fundamentado em referencial teórico; 3) Apreensão do conteúdo verbal expresso pelas profissionais dos aspectos significativos de suas percepções, para a compreensão e análise de suas vivências; 4) Identificação e classificação dos aspectos que apresentavam convergências de conteúdo, de vários depoimentos expressos por diferentes participantes, buscando aquilo que se mostrava constante nos depoimentos; 5) Agrupamento das locuções de efeito para a construção das subcategorias, categoria e temática; 6) Apresentação da estrutura do fenômeno contendo a temática, a categoria e as subcategorias; e 7) Análise compreensiva dos dados significativos da análise ${ }^{(12)}$.

A pesquisa atendeu às exigências éticas da resolução $n^{\circ} 466$, do Conselho Nacional de Saúde de 2012, com a aprovação pelo Comitê de Ética em Pesquisa, sob parecer consubstanciado no 932.998/2014 e CAAE no 37557214.6.0000.553. 


\section{RESULTADOS E DISCUSSÃO}

Entre as três enfermeiras e oito técnicas de enfermagem, que participaram da pesquisa, oito eram do gênero feminino, com média de idade de 41 anos (mínima de 31 e máxima de 52 anos). 0 tempo de formação variou de 10 a 31 anos e trabalhavam na instituição entre dois e 31 anos. As três enfermeiras tinham especialização e, entre as técnicas de enfermagem, sete informaram apresentar cursos na área hospitalar, sendo que um técnico tem formação superior em teologia.

A leitura flutuante proporcionou a apreensão do sentido global da vivência de enfermeiras e técnicas de enfermagem nas relações de cuidado. Assim, foi possível apreender os sentidos e os significados para a construção das subcategorias e categoria empíricas e, posterior, da temática que estrutura o fenômeno situado.

Temática: Respeito aos direitos humanos nas relações de cuidado por profissionais de enfermagem

A temática que estrutura o fenômeno situado compreende a categoria: vivenciando o respeito aos direitos humanos na prestação de cuidados, e as subcategorias: revelando esforços para garantir o atendimento aos direitos humanos na prestação de cuidados; revelando a vivência diante dos limites de cuidado e; revelando o preconceito nas relações de cuidados. Emergiram aspectos dos direitos humanos vivenciados por essas profissionais no cuidado à pessoa hospitalizada em setor de urgência.

\section{Categoria: Vivenciando o respeito aos direitos humanos na prestação de cuidados}

A categoria descreve como as profissionais de enfermagem vivenciam o cuidado nas relações com os usuários os quais fundamentam sua prática no diálogo e acolhimento e consideram os direitos humanos essenciais na busca da integralidade do cuidado.

Nesta categoria têm-se as subcategorias: Acolhendo o usuário do serviço de saúde considerando os direitos humanos nas relações de cuidado; Respeitando o diálogo entre profissionais de enfermagem e usuários no serviço hospitalar; Buscando o cuidado integral dos usuários no serviço de urgência hospitalar; Revelando esforços para garantir os direitos humanos na prestação de cuidados; Vivenciando os limites relacionados ao cuidado ao usuário por profissionais de enfermagem; Desvelando o preconceito nas relações de cuidados dos usuários.

\section{Subcategoria 1: Acolhendo o usuário do serviço de saúde considerando os direitos humanos nas relações de cuidado \\ Para as profissionais de enfermagem, o} atendimento aos direitos humanos do usuário hospitalizado na condição de fragilidade necessita de acolhimento, e o profissional deve garantir o cuidado integral.

"Então eu acho que segue mais ou menos assim, por essa vertente aí e, principalmente, para pessoa que está hospitalizada, nos momentos que está mais debilitado, está mais precisando de um acolhimento, [...]" (Açafrão).

"Então quando eles chegam até nós, eles já chegam já um pouco armado, então há uma necessidade de você acolher essa pessoa, de você cuidar para ela perceber que ela é valorizada ali. [...] e nós tivemos uma maneira de acolher, de mostrar a ele que o problema foi em outro lugar não foi conosco e nós tentamos, com jeito, conseguimos acolher a pessoa" (Frésia).

Entre as enfermeiras e técnicas de enfermagem, os grupos sociais de baixa renda não têm os direitos humanos respeitados e são expostos a cuidado insipiente. Há um esforço cotidiano dessas profissionais para acolher e auxiliar o acompanhante do usuário, como forma de colaborar na recuperação do paciente e que a forma, como essas profissionais se aproximam dos usuários, traz significado sobre o cuidado de enfermagem.

"As pessoas, principalmente da classe sofrida, eles não têm costume de ser bem tratado, de ser chamado pelo nome, [...] Eles nem sabem o nome, convive com a pessoa vários tempos e não sabe o nome, [...]" (Frésia).

"Eu tenho tentado a cada dia também acolher o acompanhante eu tento ajudar no resultado, [...] até na dinâmica do tratamento do paciente, que você acolhe bem, o acompanhante se sente mais tranquilo. [...] que, às vezes, a pessoa quer sair da instituição, na realidade pra não estar criando desgaste para o acompanhante que eles acham que está sendo um peso, [...] que a pessoa tem que estar sentado com ele, $[. .$.$] "$ (Frésia).

"E a pergunta tradicional da enfermagem: ta tudo bem? Ta sentindo alguma coisa? O senhor quer alguma coisa? Então isso marca as pessoas" (Frésia). 
Subcategoria 2: Respeitando o diálogo entre profissionais de enfermagem e usuários no serviço hospitalar

Há necessidade de cuidado e dedicação ao paciente hospitalizado, voltado para a essência do ser. Entre usuário e profissional é preciso diálogo e escuta, por ser uma das formas de respeito aos direitos humanos. E fornecer informações aos usuários sobre os cuidados e serviços propiciam aproximação e subsídio para o diagnóstico, acompanhamento e tratamento.

"E no caso [...] paciente hospitalizado requer mais cuidados, mais é [...] dedicação e pensando sempre no seu 'eu' né?!" (Gerbera).

"Pelo tempo que a gente para conversando, dando risada, às vezes, quebra até o protocolo do técnico de enfermagem, mas a gente senta, conversa, dá risada com as pessoas, [...] eles terminam se abrindo, a gente termina descobrindo mais informações que vão contribuir com o diagnóstico correto do médico do que a própria entrevista da anamnese do médico, então acho que isso é importante" (Frésia).

"É [...] auxiliando e participando diretamente, informando a ele todos os cuidados que são prestados" (Dália).

"A maneira de abordar as pessoas também é importante, às vezes, a pessoa tem algum problema que ele se sente fechado pra conversar com o médico, o jeito do médico bem mecânico de atender, de falar. E a enfermagem tem aquela questão de se sentar, de conversar, às vezes, passa alguém e pergunta: é seu parente?" (Frésia).

"Pode-se dizer: existe conforto em uma cadeira? [...] se naquele momento só tiver a cadeira, nós vamos conversar com nosso cliente: olha! No momento estamos superlotados, vamos conseguir tirar sua dor, porém a acomodação no momento é cadeira, não temos outra pra oferecer, assim que surgir a vaga o senhor, a senhora será transferido para um local melhor! [...] e da minha parte, na minha área de técnico, é essa: dar as mínimas condições de higiene, de conforto" (Urze).

\section{Subcategoria 3: Buscando o cuidado integral dos usuários no serviço de urgência hospitalar}

O cuidado integral considera a pessoa sob cuidados como ser humano vulnerável e com necessidades particulares. $O$ usuário possui direito à integralidade do cuidado, e as profissionais de enfermagem precisam garantir o respeito aos direitos humanos, mesmo diante dos limites institucionais.
"Vendo o cliente como um todo, não só o vendo como uma pessoa, que necessita de cuidado, não só do profissional de enfermagem e, sim, como um ser humano que necessita de atenção, carinho, cuidado e sensibilidade, porque além da carência, há o abandono por parte dos familiares, o que faz que ele fique debilitado, [...]" (Jacinto).

$\mathrm{O}$ atendimento aos direitos humanos, por parte da equipe de enfermagem, favorece a garantia da privacidade, segurança e respeito à autonomia e à decisão do usuário dos serviços de saúde.

"Vivenciamos desde o momento que o paciente entra na instituição chamando ele pelo nome próprio [...] mostrando que ele tem uma identidade. Até a questão da privacidade, da segurança nos cuidados que a gente tem, e até no direito dele se recusar em alguns cuidados que são feitos na instituição" (Rosa Champanhe).

"Porque a gente compreende que ele tem direito a uma assistência integralizada, [...]" (Girassol).

\section{Subcategoria 4: Revelando esforços para garantir os direitos humanos na prestação de cuidados}

As participantes revelaram esforços para garantir o atendimento aos direitos humanos no cuidado do usuário e da família, que é objetivada na lei.

"Mas. na realidade, assim, são garantidos por lei, também, os direitos humanos hoje" (Rosa Champanhe).

"Na minha vivência de três anos numa emergência pública, eu procuro esforçar-me ao máximo de manter esse direito ao ser humano, a pessoa que nos procura, né?" (Urze).

"Na minha vivência da enfermagem, procuro exercer a assistência ao paciente baseada nos direitos de cada um e vejo que meus colegas de profissão atuam nesse mesmo sentido" (Bromélia).

"É... outra coisa também que a gente tem tentado, falar a gente porque eu acho que meus colegas também têm se esforçado nesse sentido [..., sempre gosto de falar no plural, mas assim, aquela preocupação também do acolhimento da família. [...] Então esse esforço, e também outra coisa que nós devemos sempre ter esforço pela perfeição porque nós devemos estar sempre aprendendo a cada dia, mas acaba sendo [...]" (Frésia). 


\section{Subcategoria 5: Vivenciando os limites relacionados ao cuidado ao usuário por profissionais de enfermagem}

Entre as profissionais, são reveladas limitações nos cuidados e considera-se a integridade física e psicológica do usuário, além da escassez de profissionais de enfermagem quanto à demanda, como limite que interfere na eficácia do respeito aos direitos humanos. Todavia, apesar das limitações encontradas na instituição, elas buscam garantir o respeito a esses direitos no processo de cuidar.

"Precariamente, né? [...] os direitos humanos no hospital público é uma prática ineficaz porque $o$ paciente não tem sua integridade física respeitada, não tem a integridade, não tem o... (pausa), como eu posso falar... (pausa), não tem, não tem a integridade física, psicológica" (Orquídea).

"[...] então prestar os melhores cuidados possíveis, apesar das dificuldades que a instituição ou o sistema vem impor a gente, né [...]" (Açafrão).

"Mas infelizmente esse direito não tem sido respeitado, em alguns casos, por conta dos profissionais, mas eu creio que na maioria dos casos, pelo fato de ser poucos funcionários pra uma demanda grande" (Magnólia).

\section{Subcategoria 6: Desvelando o preconceito nas relações de cuidados dos usuários}

$\mathrm{O}$ preconceito emergiu no atendimento e nas relações de cuidados das profissionais com os usuários, o que infringe os direitos humanos.

"Muitas pessoas já chegam ao serviço com esse "preconceito" achando que: não! vou chegar, vai demorar muito e nem sempre se verifica isso, né?" (Urze).

"Têm pessoas que têm uma visão até de homossexual do profissional de saúde pelo tratamento. As pessoas começam a olhar diferente, porque eles não têm costume" (Frésia).

A maioria das enfermeiras e técnicas de enfermagem que atuam no setor de urgência são mulheres, o que converge com outros estudos ${ }^{113-}$ ${ }^{14)}$, incluindo outros serviços de urgência ${ }^{(15)}$. Essa predominância do gênero feminino tem relação com a atividade de cuidado, como socialmente emanado, pelas mulheres nos lares e a constituição histórica da enfermagem. Eleva a necessidade de reconhecer o cuidado na perspectiva ontológica por um grupo que ainda é socialmente demarcado por lutas de liberdades, inclusive de expressão, para que seja fomentada uma prática para além da técnica, mais humanizada e solidária.

O cuidado implica atividades desenvolvidas pelas profissionais de enfermagem para e com o outro, fundamentada em conhecimento, pensamento crítico, habilidade, intuição e criatividade, que favoreça a promoção, manutenção e recuperação da dignidade e totalidade da pessoa. Nas relações de cuidado, é necessário envolvimento e compromisso com o ser humano, assim como cuidado ético baseado em competência, habilidade, atitude profissional e valorização da subjetividade de cada pessoa cuidada $^{(16)}$.

Como visto neste estudo, o cuidado das profissionais de enfermagem é fundamentado no acolhimento e diálogo, o que é corroborado com a Carta de Direitos dos Usuários da Saúde, que, em seu artigo 4, explicita sobre a qualidade do atendimento em saúde acolhedor e humanizado, assegurado como direito de qualquer pessoa ${ }^{(17)}$. Essas características, descritas pelas participantes, contribuem para a convergência da garantia do atendimento à saúde na urgência hospitalar e, concomitantemente, respeito aos direitos humanos.

No entanto as falas também refletem um aspecto relacional de endurecimento quanto às experiências prévias da pessoa a ser cuidada, que podem incidir na relação com os profissionais de enfermagem. $E$, na perspectiva de melhorar a interação, as profissionais devem desenvolver habilidades sociais e, assim, elevar a capacidade em lidar com os desafios das suas atividades ${ }^{(18)}$.

Além de uma visão reducionista da saúde, a sua compreensão, como direito das pessoas, exige do Estado a garantia de cuidados de saúde acessíveis e de qualidade, assim como a promoção de ações que venham interferir nos seus determinantes. O direito à saúde precisa ser efetivado sem discriminação de idade, raça, etnia ou outra condição ${ }^{(4)}$. E, como visto neste estudo, as profissionais de enfermagem sentem-se responsáveis na tentativa de efetivar estratégias que assegurem esse direito às suas práticas.

A saúde, como destaque para a vida digna, é uma reivindicação ética, que se relaciona com o desenvolvimento da cidadania, em uma sociedade democrática, assim, assume-se a relação dos direitos humanos e a saúde ${ }^{(19)}$. Logo garantir condições que favoreçam a preservação da saúde converge com a garantia do exercício e da proteção dos direitos humanos. 
O acolhimento se aproxima de um exercício da enfermagem por envolver uma prática de relações interpessoais, com o propósito de conforto, reconhecimento do usuário como sujeito de condições objetivas e subjetivas e que está inserido em um contexto de vida. Esse acolhimento deve ser baseado na escuta qualificada, identificação de necessidades, responsabilização e comprometimento com as necessidades do outro e do trabalho em equipe ${ }^{(20)}$.

Estudo aponta que a assistência de enfermagem possibilita diálogo com o ser cuidado, visto que o vínculo entre profissional e usuário é fator importante no cuidado ${ }^{(16)}$. Essa necessidade de diálogo desvelado pelas participantes deste estudo se relaciona com o fortalecimento das tecnologias leves no cuidado em saúde, como uma premissa que alcança os serviços de urgência e urgência e constitui-se em formas de assegurar a relações de confiança e comunicação efetiva ${ }^{(21)}$.

Todavia os serviços de urgência apresentam deficiências em estruturas e processos que incidem em resultados, que contrastam com a garantia dos direitos a saúde de qualidade, como alta demanda, sobrecarga de trabalho, inadequação da estrutura física, deficiência de recursos materiais e humanos, ainda a postura autoritária de alguns profissionais ${ }^{(21)}$.

No que diz respeito à essa realidade, as profissionais de enfermagem ainda se deparam com a necessidade de instituir o cuidado integral, produto das relações existentes entre os vários profissionais e respectivos planos de cuidados ofertados aos usuários, o que deve favorecer a integralidade. $O$ gerenciamento de enfermagem é uma das estratégias à efetivação desse cuidado e está voltado à resolução de problemas, em acordo com o atendimento das necessidades de saúde.

Contudo as dificuldades estruturais ou funcionais limitam esse gerenciamento, como relacionado à estrutura organizacional inadequada, dicotomia entre gerenciamento e cuidado e falhas na comunicação ${ }^{(14)}$, assim, como a dinâmica de trabalho de setores como o de urgência, no qual a relação de cuidado, às vezes, é interrompida, rápida e ocorre de forma variada, a depender das demandas e organização dos serviços.

O cuidado integral é um direito dos usuários que procuram as organizações de saúde, independente das suas condições, de sua vulnerabilidade (física, psíquica, econômica e social) ${ }^{(17)}$, e um dos princípios das profissionais de enfermagem é assegurar esse direito ${ }^{(22)}$. Assim, quando as enfermeiras e técnicas de enfermagem deste estudo visualizam o ser humano em sua totalidade, elas devem considerar as pessoas em todas as suas dimensões, como forma de elevar o respeito aos direitos humanos no cuidado, mesmo diante das limitações institucionais emergidas como déficit de profissionais de saúde para atender as demandas.

Por meio da compreensão sobre a vivência das enfermeiras e técnicas nas relações de cuidados, o diálogo com o usuário é uma das formas de aproximação com os direitos humanos. O diálogo com escuta qualificada nestas relações constitui-se como uma ferramenta indispensável na garantia de vivências e do respeito aos direitos humanos. Para tanto, é importante que a abordagem inicial das profissionais de enfermagem seja por meio de uma comunicação empática que evite desvios no atendimento aos direitos da pessoa e contemple o cuidado em sua integralidade.

A compreensão que os Direitos Humanos são diretrizes que expressam os valores e necessidades humanas, para subsidiar a construção de dispositivos normativos e auxiliarem na regulamentação e na defesa desses direitos, para a sua proteção, na área da saúde, é fundamental o conhecimento sobre as normativas que contenham indicações à defesa dos direitos humanos e à dedicação dos profissionais de enfermagem, para considerar o respeito a esses direitos, pelo acolhimento e aprendizado no cotidiano do cuidado.

Como evidenciado, o respeito aos direitos humanos permeia a busca pela integralidade do cuidado. Porém, quando esses direitos se reduzem a um ponto de encontro de direitos, dificulta a compressão da dimensão do real sentido da sua necessidade, como a luta contra as injustiças sociais $^{(19)}$. As violações aos direitos humanos podem ter graves consequências para a saúde e abalam os alicerces da justiça social, porque elas levam à dor, à falta de esperança, à sensação de abandono social, à iniquidade ${ }^{(19)}$. O respeito a esses direitos foi desvelado como uma necessidade a ser almejada pelas pessoas.

As profissionais vivenciam limites nas relações de cuidado com o usuário e consideraram ineficazes as condições estruturais e organizacionais para a garantia da integridade física e psíquica do usuário e o respeito aos direitos humanos. Porém, apesar dos limites desvelados, revelaram um projeto de busca para 
garantir o respeito aos direitos humanos na execução das suas atividades. $O$ atendimento aos direitos humanos favorece a garantia da privacidade, segurança e respeito à autonomia e decisão.

Por compreender que a existência humana tem valor intrínseco, o respeito pela humanidade relaciona-se à percepção de justiça e à dignidade humana a ela incorporada. Essa dignidade, por sua vez, é inseparável da justiça e dos direitos humanos $^{(4)}$. E a privacidade reforça outros direitos, incluindo $\mathrm{o}$ da igualdade e não discriminação e liberdade de expressão. A privacidade é imprescindível para a proteção da dignidade humana, constituindo-se como um dos temas da DUDH ${ }^{(1)}$. Corroborado com este estudo, ao desvelar respeito, justiça e privacidade, como fundamentos dos direitos humanos devem ser exercidos no atendimento aos usuários nos espaços de urgência.

Considerar, no processo de cuidar, os itens contidos na Declaração Universal dos Direitos Humanos $^{(1)}$, no Código de ética dos profissionais de enfermagem (CEPE) ${ }^{(22)}$ e na Carta de Direitos dos Usuários da Saúde ${ }^{(17)}$, sobre atendimento sem discriminação, além de respeitar à dignidade humana, é fundamental para salvaguardar e proteger os usuários contra as violações dos direitos humanos proporcionando assistência digna e de qualidade.

As profissionais de enfermagem não devem sobrepor seus valores aos dos usuários, nem utilizá-los como forma de determinar imposições éticas ou morais quanto às necessidades e percepções de quem busca cuidados. Nas relações de cuidado, a equipe de enfermagem deve considerar o respeito aos direitos humanos por sua garantia, como a de não sofrer discriminação ou preconceito. $E$, no cuidado aos usuários em serviço de urgência, existe também uma demanda relacionada à necessidade de envolver a família.

Estudo explicita a satisfação de familiares com a equipe e as estratégias de acolhimento para o apoio durante a vivência do período de internamento do seu familiar ${ }^{(23)}$. Todavia, ainda é um desafio a ser superado pelas profissionais de enfermagem quanto à participação do usuário e acompanhante na tomada de decisão, o conhecimento das necessidades de cuidados, sua satisfação e a resolutividade do cuidado ${ }^{(13)}$. Neste estudo, foi revelada a necessidade de garantir os direitos humanos na atenção as demandas do usuário e de sua família, como maneira de impactar na recuperação do cliente.
Como visto, embora seja um desafio a participação de usuários e familiares nas decisões sobre sua saúde, isso deve ser garantido e respeitado, em todos os ambientes hospitalares, como em setores de urgência, pois relaciona-se ao respeito aos direitos dos usuários, além de fazer parte da integralidade do cuidado que deve ser uma das prioridades no atendimento na rede do SUS.

Nesse sentido, os direitos fundamentais dos usuários de saúde são constantemente desrespeitados e, na maioria das vezes, essas pessoas nem se dão conta que estão sendo privadas de seus direitos, principalmente por carência de conhecimento ${ }^{(9)}$. Isso foi desvelado neste estudo, quando as profissionais de enfermagem informaram que se preocupam com a garantia dos direitos dos usuários e que sempre se esforçam para que todos os seus direitos sejam respeitados, além de reforçar que esses direitos são garantidos por lei.

Em estudo realizado no Paquistão constatou-se que a educação sobre cuidados de saúde entre os usuários pode melhorar a consciência e a prática dos direitos dos usuários nos hospitais ${ }^{(24)}$. Tão logo, considera-se importante associar as preocupações e os esforços das profissionais de enfermagem, para a garantia dos direitos dos usuários como na ampliação de informações, por meio de ações de educação em saúde e, sobretudo, em direitos humanos e dos usuários da saúde, em contexto hospitalar.

Além disso, essa preocupação da equipe de enfermagem é essencial à efetividade do cuidado, pois, quando se pensa em garantia de direitos, suscita o cuidar do outro de forma humanizada e sensível, respeitar suas subjetividades e se colocar no lugar do outro. Ademais, esse cuidado vai além do biológico, para atender as demandas emocionais, psicológicas e sociais. Desse modo, com base nos direitos humanos e morais, deve-se tomar as medidas necessárias para apoiar os usuários dos serviços de saúde a receberem cuidados de qualidade ${ }^{(24)}$.

Neste estudo, ficou explícito que o número inadequado de profissionais de enfermagem, para a demanda de usuários no serviço de urgência, prejudica $o$ atendimento e compromete a qualidade dos serviços prestados e a garantia de direitos. Isso é corroborado com o estudo ${ }^{(25)}$, o qual explicita que o dimensionamento de pessoal, a carga horária e as condições de trabalho são fatores que interferem na qualidade da assistência 
e, consequentemente, na garantia dos direitos dos usuários dos serviços de saúde.

Dessa forma, os serviços de saúde precisam se adequar às normas de dimensionamento de pessoal, para que os direitos humanos sejam garantidos e a qualidade da assistência não seja afetada. Todavia, para que esses direitos sejam respeitados, é necessário que o Estado garanta as condições necessárias para as demandas dos serviços e usuários, a população ser sensibilizada sobre seus direitos em convergência com o que propõe a participação social na saúde e aos profissionais de enfermagem estarem atentos sobre a sua responsabilidade social na defesa dos direitos das pessoas.

\section{CONCLUSÃO}

Desvelou-se a prática social das profissionais de enfermagem que atuavam em unidade de urgência, a partir de um fazer cotidiano, com respeito aos direitos humanos na busca da integralidade do cuidado aos usuários do serviço. Assim, foi possível compreender que essas profissionais no cuidado buscavam garantir a dignidade e o respeito aos direitos humanos, mesmo diante as limitações institucionais e inadequações estruturais e organizacionais dos serviços de urgência, em que desenvolviam suas atividades e que, de alguma forma, influenciam no cuidado.

Os aspectos relacionais e de qualidade da assistência emergiu no estudo, enfatizando a valorização do uso da tecnologia leve em contextos de cuidado em unidades de urgência. Assim, as ações das profissionais de enfermagem demonstraram aspectos que convergem com a implementação de aspectos presentes na Carta dos Direitos dos Usuários da Saúde, refletindo a necessidade de reconhecer as ações positivas, em um movimento de visibilidade e encorajamento das práticas que promovam a garantia dos direitos dos usuários da saúde, mediante o reconhecimento dos direitos humanos.

O estudo contribuiu para a ampliação dos conhecimentos no campo da saúde e, em particular, para a área da enfermagem, assim como possibilitou reflexões que subsidiam a tomada de decisões da equipe de saúde, como em serviços de urgência. Para a enfermagem, como evidenciado, mesmo as profissionais se deparando com fatores que comprometem a garantia do respeito aos direitos humanos em sua prática, elas cuidam de forma humanizada, conforme as necessidades dos usuários e fundamentam suas ações no acolhimento, o que fortalece a integralidade do cuidado no contexto do SUS e favorece sua atuação de forma responsável e sensível quanto aos direitos humanos.

Como limitação do estudo, tem-se o local, por se tratar apenas do setor de urgência de um hospital público. Sugere-se que novos estudos sejam realizados, em outros setores do ambiente hospitalar, onde ocorre o cuidado de enfermagem, especialmente no atendimento às populações vulneráveis. Deve-se ainda incluir os serviços de baixa complexidade. Recomendam-se estudos que compreendam sobre o respeito aos direitos humanos nas relações de cuidado na percepção dos usuários da saúde.

\section{REFERÊNCIAS}

1- Organização das Nações Unidas. Declaração Universal dos Direitos Humanos. Paris: ONU; 1948 [citado em 14 out 2020]. Acesso em: http://www.un.org/en/documents/udhr/index.sh $\underline{\mathrm{tml}}$

2- Rios IC. Humanização: A essência da ação técnica e ética nas práticas de saúde. Rev Bras Educ Med. 2009;33(2):253-61. DOI: 10.1590/S0100-55022009000200013

3- Fortunato BC, Destro CRF. A construção do direito à saúde no Brasil: $O$ plano de fundo antecente à sua positivação constitucional. Revista de Direitos Sociais, Seguridade e Previdência Social 2019;5(1):18-37. DOI: 10.26668/IndexLawJournals/25259865/2019.v5i1.5454

4- Oliveira MHB, Vianna MB, Teles N, Machado FRS, Ferreira AP, Telles FSP, et al. Direitos humanos e saúde: 70 anos após a Declaração Universal dos Direitos Humanos. Revista Eletrônica de Comunicação, Informação e Inovação em Saúde 2018;12(4):370-4. DOI: 10.29397/reciis.v12i4.1667

5- Barreto ML. Desigualdade em saúde: Uma perspectiva global. Ciênc Saúde Coletiva 2017;22(7):2097-108. DOI: 10.1590/141381232017227.02742017

6- Silva DN, Palma D. Direitos humanos: Perspectivas, mediações, práticas comunicativas: Uma apresentação. Trab Linguist Apl. 2018;57(2):601-15. DOI: 10.1590/010318138652964411831

7- Nogueira LS, Sousa RMC, Guedes ES, Santos MA, Turrini RNT, Cruz DAL. Burnout and nursing work environment in public health institutions. 
Rev Bras Enferm. 2018 71(2):358-65. DOI: 10.1590/0034-7167-2016-0524

8- Ministério da Saúde (BR). Acolhimento e classificação de risco nos serviços de urgência. Brasília: Ministério da Saúde; 2009.

9- Silva Neto ET, Ventura CAA. O ensino de direitos humanos na educação profissional em enfermagem. Rev COCAR 2019 [citado em 14 out 2020]; 13(25):325-41. Acesso em: https://periodicos.uepa.br/index.php/cocar/articl e/view/2163/1084

10- Organização das Nações Unidas (BR). Projeto em Porto Alegre usa encenação para conscientizar profissionais de saúde sobre discriminação. Brasília: ONU; 2018.

11- Gil AC. Métodos e técnicas de pesquisa social. 6a ed. São Paulo: Atlas; 2008.

12- Vietta EP. Configuração triádica, humanistaexistencial-personalista: UMA abordagem teóricametodológica de aplicação nas pesquisas de enfermagem psiquiátrica e saúde mental. Rev Latino-Am Enferm. 1995;3(1):31-43. DOI: https://doi.org/10.1590/S0104-

11691995000100004

13- Martins PF, Perroca MG. Care necessities: The view of the patient and nursing team. Rev Bras Enferm. 2017;70(5):1026-32. DOI: 10.1590/00347167-2016-0197

14- Sousa SM, Bernardino E, Crozeta K, Peres AM, Lacerda MR. Integrality of care: Challenges for the nurse practice. Rev Bras Enferm. 2017;70(3):52936. DOI: https://doi.org/10.1590/0034-71672016-0380

15- Cuduro FLF, Macedo SMK. Evaluation of the working environment between nursing professionals in an urgent and emergency unit. Enferm Glob. 2018;50:375-87. DOI: 10.6018/eglobal.17.2.283991

16- Santos AG, Monteiro CFS, Nunes BMVT, Benício CDA, Nogueira TT. O cuidado em enfermagem analisado segundo a essência do cuidado de Martin Heidegger. Rev Cubana Enferm. 2017 [citado em 13 out. 2020]; 33(3). Acesso em: http://revenfermeria.sld.cu/index.php/enf/article /view/1529/295

17- Conselho Nacional de Saúde (BR). Carta dos direitos e deveres da pessoa usuária da saúde. Brasília: Conselho Nacional de Saúde; 2017.

18- Montezeli JH, Haddad MCFL, Peres AM, Matsuda LM. Approximations between social skills, nursing care management and complex thinking. Rev Min Enferm. 2018;22:e-1092. DOI: $\underline{10.5935 / 1415-2762.20180022}$
19- Oliveira MHB, Vianna MB, Schütz GE, Teles N, Ferreira AP. Human rights, justice and health: Reflections and possibilities. Saúde Debate 2019;43(4):9-14. DOI: 10.1590/0103$11042019 s 401$

20- Costa PCP, Garcia APR, Toled VP. Welcoming and nursing care: A Phenomenological Study. Texto Contexto-Enferm. 2016;25(1):e4550015. DOI: 10.1590/0104-07072016004550014

21- Sousa KHJ, Damasceno CKC, Almeida CAP, Magalhães JM, Ferreira MA. Humanization in urgent and emergency services: Contributions to nursing care. Rev Gaúcha Enferm. 2019;40:e20180263. DOI: $\underline{0.1590 / 1983-}$ 1447.2019.20180263

22- Conselho Federal De Enfermagem. Resolução COFEN no 564/2017. Aprova o novo Código de Ética dos Profissionais de Enfermagem. Brasília: COFEN; 2017 [citado em 14 out 2020]. Acesso em: http://www.cofen.gov.br/resolucao-cofen-no5642017 59145.html

23- Fettermann FA, Aranda AC, Rosa AB, Donaduzzi DSS. Acolhimento e humanização dos familiares em unidade de tratamento intensivo adulto: Revisão de literatura. Revista Eletrônica Acervo Saúde 2019;11(12):e507. DOI: 10.25248/reas.e507.2019

24- Tabassum T, Ashraf M, Thaver I. Hospitalized patients' awareness of their rights-a cross sectional survey in a public and private tertiary care Hospitals of Punjab, Pakistan. J Ayub Med Coll Abbottabad 2016 [cited 2020 Dec 16] ;28(3):5826. Available in: em: http://jamc.ayubmed.edu.pk/index.php/jamc/art icle/view/607/421

25- Silva-Batalha SEM, Melleiro MM. Cultura de segurança do paciente: Percepções da equipe de enfermagem. HU Rev. 2016 [citado em 14 out 2020]; 42(2):133-42. Acesso em: https://periodicos.ufjf.br/index.php/hurevista/art icle/view/2518/872

Nota: Artigo proveniente dos resultados da dissertação de mestrado Intitulada "Direitos Humanos vivenciados pelos profissionais de enfermagem no cuidado à pessoa hospitalizada", do Programa de Pós-Graduação em Enfermagem e Saúde da Universidade Federal da Bahia.

Recebido em: $16 / 10 / 2020$

Aprovado em: $21 / 12 / 2020$

Endereço de correspondência:

Tyciana Paolilo Borges

Universidade Salvador. Av. Luís Viana Filho, 3146 / 3100, CEP 41.720-200 - Pituaçu, Salvador, Bahia, Brasil.

E-mail: tycipb@hotmail.com 